\title{
MÚLTIPLOS EPISÓDIOS DE INFARTO AGUDO DO MIOCÁRDIO APÓS USO DE ANTICOAGULANTE - RELATO DE CASO
}

\author{
MULTIPLE ACUTE MYOCARDIAL INFARCTION EPISODES AFTER \\ ANTICOAGULANT USE - CASE REPORT
}

Gustavo Moreira Clivatti1; João Pedro Pereira da Cunha2; Gustavo Lenci Marques3; Caio Cesar

Cervi Lagana2; Luciana de Cerjat Bernardes Pereira da Cunha4; Gibran Avelino Frandoloso4;

\section{RESUMO}

OBJETIVO: Descrever um caso de paciente com trombocitopenia induzida por heparina (TIH) tipo II, que se manifestou através de consecutivos quadros de infartos agudos do miocárdio. RELATO DE CASO: Trata-se de uma paciente do sexo feminino, 70 anos, admitida no HC-UFPR por quadro de infarto agudo do miocárdio (IAM), duas semanas após internamento hospitalar por pneumonia e insuficiência cardíaca descompensada, manejadas com antibioticoterapia, heparina e diuréticos. Evoluiu com quadro de plaquetopenia a esclarecer e dois episódios subsequentes de IAM. Após a retirada da heparina, evoluiu com estabilização clínica - aumento do número de plaquetas, sem novos eventos trombótico e regularização dos testes laboratoriais. Recebeu alta hospitalar e, no retorno ambulatorial, apresentou anticorpos anti-plaqueta positivos e uma revisão de prontuário com história de múltiplas exposições a heparinas não fracionada e de baixo peso molecular. CONCLUSÃo: Diante do grande número de pacientes expostos à heparina, seus principais efeitos colaterais, dentre os quais a TIH, precisam ser conhecidos. Deve-se atentar para a possibilidade de a heparina possuir associação causal com IAM, quando associado à trombocitopenia, visto que a tendência nessas situações é de se manter a medicação a fim de evitar quadros trombóticos futuros.

Descritores: heparina; infarto do miocárdio; trombocitopenia.

\section{ABSTRACT}

OBJECTIVE: Report a case of patient with heparin induced thrombocytopenia (HIT) type II, which was expressed through consecutive episodes of acute myocardial infarction. CASE REPORT: A 70-year-old woman was admitted to hospital care due to an episode of acute myocardial infarction two weeks after hospitalization for pneumonia and decompensated heart failure, when she was managed with antibiotics, heparin and diuretics. She evolved with thrombocytopenia and two subsequent episodes of acute myocardial infarction. After discontinuing heparin, she progressed with clinical stabilization - an increase of platelets, without new thrombotic frames and regularization of laboratory tests. Patient was then discharged and during outpatient follow showed positive anti-platelet antibodies and a retrospective analysis of multiple exposures to unfractionated and low molecular weight heparins. CONCLUSION: Considering the large number of patients exposed to heparin, its major side effects must be known. Care must be taken to the possibly of heparin be a trigger to procoagulant state, resulting in acute myocardial infarction, for example, since a trend in these situations is to maintain the drug to prevent future thrombotic episodes.

Keywords: heparin; myocardial infarction; thrombocytopenia.

1- Acadêmico de Medicina, Hospital de Clínicas, Universidade Federal do Paraná - UFPR.

2- Médico Residente, Hospital de Clínicas, Universidade Federal do Paraná - UFPR.

3- Professor, Hospital de Clínicas, Universidade Federal do Paraná - UFPR.

4- Médico, Hospital de Clínicas, Universidade Federal do Paraná - UFPR. 


\section{INTRODUCTION}

Heparin induced thrombocytopenia (HIT) is a major adverse drug reaction of heparin, which occurs in about $5 \%$ of patients exposed to the drug. It is a result of antibodies production against a complex of heparin and platelet factor 4 (PF4), that activates platelet, leading to formation of arterial and venous thrombi1.

HIT can be classified in two distinct forms: type I and type II. HIT type I presents a mild and transient decrease in platelet count, that occurs within 48-72 hours of heparin treatment, without clinical implications, returning to normal spontaneously. HIT type II has a clinical presentation of thrombosis and thrombocytopenia, and this risk of thrombus formation exists until heparin is metabolized, excreted and another anticoagulant is set $u^{2}$.

The aim of this case report is describe an event of heparin induced thrombocytopenia type II in a patient manifesting consecutive frames of acute myocardial infarction, and perform literature review to emphasize diagnosis and initial treatment of this affection.

\section{CASE REPORT}

A 70-year-old female with hypertension was complaining of chest pain at pre-hospital care. An electrocardiogram was performed, showing acute myocardial infarction with ST-segment elevation (Figure 1). She received acetylsalicylic acid (ASA) 200mg, unfractionated heparin 5000 IU subcutaneously, simvastatin $40 \mathrm{mg}$, isosorbide dinitrate $5 \mathrm{mg}$ sublingual tablet, oxygen therapy $100 \% 2 \mathrm{~L} / \mathrm{min}$. The patient was referred to coronary care unit to manage this clinical condition.

At admission, the patient was normotensive, afebrile, eupneic, with a heart rate of 85 beats/min and $90 \%$ oxygen saturation on room air. A complete physical

examination revealed no pertinent findings, except for fine inspiratory bibasilar crackles. Laboratory tests were performed revealing metabolic alkalosis, thrombocytopenia
(30,000 platelets count, Normal Value - NV - 150$\left.400,000 / \mathrm{mm}^{3}\right)$, international normalized ratio of prothrombin time (INR) 1.47 (NV 0.9-1.2), creatine kinase (CK) 1,442 U/L (NV 24-200 U/L), CK-MB 350 ng/mL (NV 0$5 \mathrm{ng} / \mathrm{mL}$ ) and troponin I 50,000 ng/mL (NV 0-0.5 ng/mL).

Her medical history included: essential arterial hypertension for 10 years; hyperurecemia; and cholecystectomy 12 years ago. A recent hospitalization was reported ( 2 weeks ago) for pneumonia and decompensated cardiac failure. She was treated with antibiotic therapy, prophylatic heparin and diuretics. The patient denied previous alcohol consumption, but she stated a 60 packyear smoking history (quit 1 year ago).

Immediately the patient was sent to the Hemodynamics and Interventionist Cardiology Sector, where clopidogrel therapy was initiated and a coronarystent was placed at proximal third of right artery, without complications. In addition, a distal trunk lesion of $30 \%$ was diagnosed. After procedure, she was referred to the Coronary Unit and treated with aspirin 100mg/day, clopidogrel $75 \mathrm{mg} /$ day and enoxaparin (prophylatic dose).

After stabilization, she was moved to cardiology ward to proceed investigation of thrombocytopenia and management of heart failure. On the sixth day of hospitalization, she developed epigastric pain, nausea and dyspnea at rest. A new electrocardiogram was performed, showing new ST segment elevation at inferior walls and V5v6.

Patient was referred back to Hemodynamics Sector. Right coronary presented many filling holes - large thrombus sized $7-8 \mathrm{~cm}$ (Figure 2); circumflex with $80 \%$ residual lesions; and $30 \%$ in tronco left coronary. Because of atypic injury, it was chosen not to carry out intervention with stent. It was also detected thrombus in the left ventricular apex, inferoapical akinesia and inferior medial hypokinesia in left ventricle.

Medical management was chosen with ASA, ticagrelor and tirofiban (for 48 hours). During this period, a slight increase in platelets count was shown, reaching 40,000 platelets.

On ninth day of hospitalization, she presented fever with a diagnosis with sepsis of unknown origin, isolating Enterococcus faecium in blood culture, and she

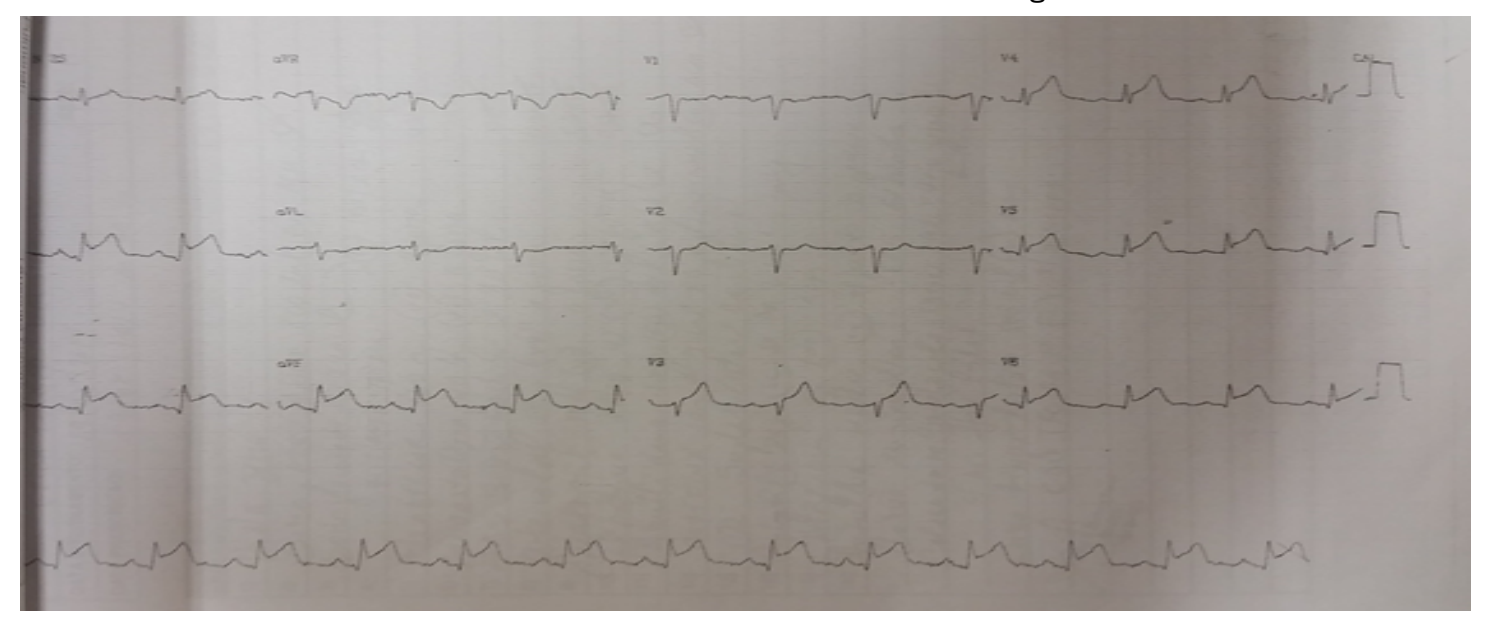

Figure 1: Pré-hospitalar eletrocardiogram presenting infarction with ST-segment elevation. 
was treated with ampicilin. On the third day of antibiotics, she presented a new episode of chest pain, nausea and sweating. Electrocardiogram was performed, showing a new ST-segment elevation (Figure 3).

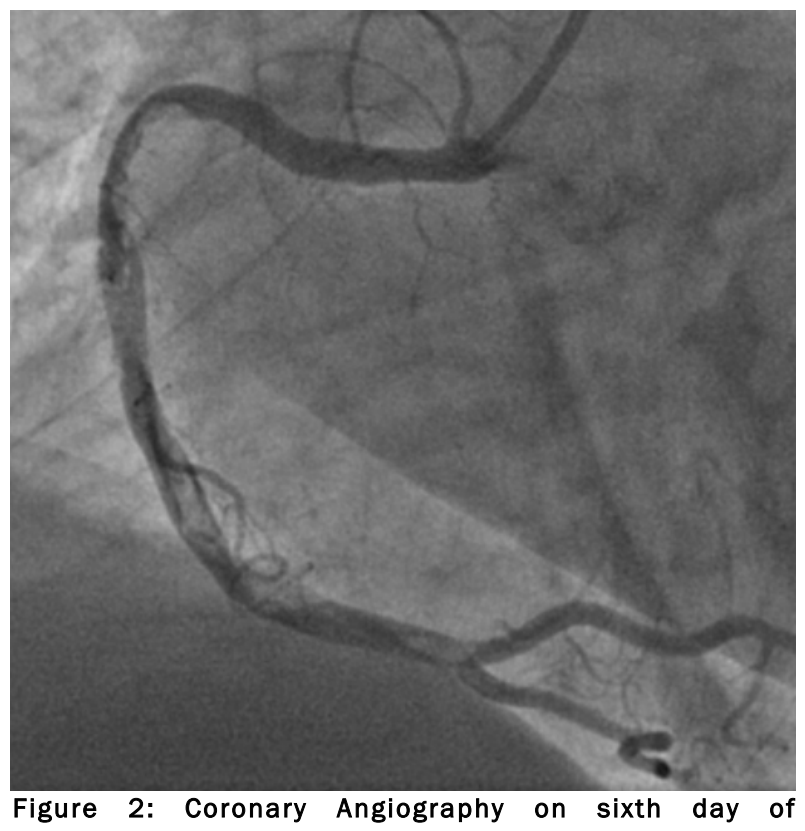
hospitalization.

Conservative therapy was again indicated, using Tirofibran, Ticagrelor, ASA, and enoxaparin full dose. Three days later, hemoglobin decreased by 3.4 points and platelet count was 28,000 . Computerized tomography was performed due to retroperitoneal hematoma suspicion, since no bleeding exteriorization was seen. It showed thrombosis involving right branch of portal vein, splenic vein, right hepatic vein and right lower lobe branch of pulmonary artery, determining perfusion defects of liver and spleen compatible with infarctions. A new catheterization three days later was carried out showing no lesions in right coronary.

After clinical stabilization, she was referred to the

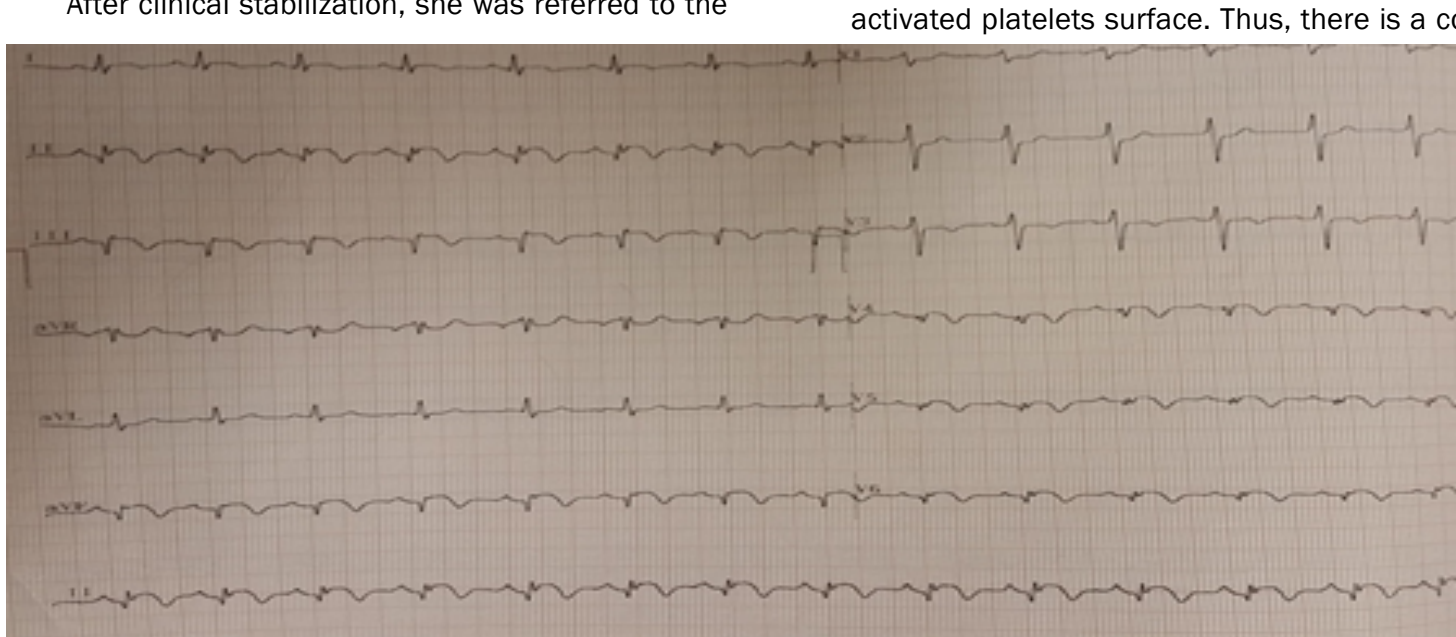

Figure 3: Electrocardiogram with new ST-segment elevation.
Internal Medicine Department, for conclusion of clinical management and investigation of thrombophilia. Warfarin was introduced and research for thrombophila was negative. Echocardiogram showed left atrium of $42 \mathrm{~mm}$, left ventricle of $40 \mathrm{~mm}$, ejection fraction of $58 \%$ and normal internal dimension of left ventricle, with inferior and lateral hypokinesia and appropriate global systolic function. With prothrombin activation time on target, enoxaparin was suspended. During five days, the platelet count evolved from 74,000 to 220,000 at hospital discharge.

Reviewing patient's medical history and previous hospitalar admission in another institution, we found out unfractionated heparin use as prophylaxis of deep vein thrombosis. At follow-up, she showed positive anti-platelet antibodies and normal platelet count using warfarin. Patient remained clinically stable, with no further new thrombotic events.

\section{DISCUSSÃO}

Defined as an adverse drug reaction, HIT is characterized by thrombocytopenia and hight risk of arterial or venous thrombosis ${ }^{3}$. It can lead to hight morbidity, with $10 \%$ of disability and it is fatal in $5-10 \%$ of cases $^{4}$. About $8 \%$ of patients produces antibodies of HIT when treated with heparin. (4) However, less than $10 \%$ of these patients will develop HIT and lower proportions symptomatic thrombosis 5 .

Risk factors include: (a) unfractionated heparin (UFH), (b) bovine UFH, (c) therapeutic doses, (d) long term use (over 5 days), (e) female (2:1), (f) elderly, (g) postoperative ${ }^{7}$.

HIT type II occurs in approximately $1 \%$ to $3 \%$ of patients exposed to heparin 8 . It is a immune disorder which leads to an increased risk of 20 to 40 times of arterial and venous tromboses ${ }^{9}$. Originally, heparin and platelet factor 4 (PF4) (a cytokine stored in alpha granules of platelets) are avoid of immunogenicity. However, when both are bound result to an antigenic macromolecule that bind on activated platelets surface. Thus, there is a conformational change that stimulates production of immunoglobulin $G$ $(\operatorname{IgG})^{10}$. The binding of IgG to the neo-antingen heparin-PF4 surface leads to a process of self-amplif ication inducing 
4Ts

Thrombocytopenia $>50 \%$ fall in platelet count or a trough of $20-100 \times 10^{9} / \mathrm{L}$

Timing

Onset within 5-10 days of exposure or $<1$ day if prior exposure within 100 days

Thrombosis

New thrombosis; skin necrosis at heparin injection sites

Other cause of No other cause identified

\section{SCORE}

1

$30-50 \%$ fall in platelet count or a trough of $10-19 \times 10^{9 / L}$ Unclear or platelet count falls after 10 days

Progressive or recurrent thrombosis; skin lesion e.g. erythema

Possible other cause

\section{0}

$<30 \%$ fall in platelet or a thought of $<10 \times 10^{9 / L}$

Platelet count falls before 5 days of exposure and without recent exposure to heparin

None

Other cause clearly identifiable severe platelet activation and the release of procoagulant factors, which results in intravascular thrombogenesis. Moreover, these immune complexes interact with monocytes and endothelial cells causing endothelial damage and tissue factor expression. By heparin metabolization, antibodies will also be extinguished, becoming undetectable 3-4 months later11.

HIT type 2 occurs in approximately 1-3\% of patients exposed to the drug ${ }^{8}$. It is an immune disorder, leading to a 20 fold increase risk of arterial and venous thromboses 9 . Originally, heparin and platelet factor 4 (PF4), a cytokine stored in platelets alpha granules, are devoid of immunogenicity. However, when bounded they result to an antigenic macromolecule that can bind on the surface of activated platelets. With that goes a conformational change that stimulates immunoglobulin $G$ (IgG) production $^{10}$.

HIT can present it clinical manifestation with a fast onset in $25 \%$ of patients, decreasing abruptly platelet count after few hours of exposure to heparin 6 . This form is attributed to prior immunization by exposure on the last 100 previous days (residual circulation of HIT antibodies). Although uncommon, a delayed onset - after 40 day - is another form of presentation. At last, the most common (65\% of patients) is thrombocytopenia after 5-10 days of exposure to heparin12.

About $50 \%$ to $75 \%$ of patients will develop thrombosis if untreated. The risk is positively correlated with thrombocytopenia severity, predicting a poor diagnosis 7 . Among complications, venous thrombosis (17\%-55\%) and arterial thrombosis (3\%-10\%) can manifest as critical organ ischemia. Others complications are stroke, pulmonary embolism and acute myocardial infarction?.

HIT may be diagnosed by a clinical scoring system. It is a pretest called "four T's", developed in $2003^{13}$ and published in $2006^{14}$ by Warkentin. This score is composed by thrombocytopenia, time, thrombosis and other causes for thrombocytopenia (table 1)1. Scoring can lead to three estimate probability: low (score of 0-3), intermediate (score of 4-5) and high risk (score of 6-8). (1) To confirm diagnosis, laboratory testing may be performed: washed platelet activation assays and commercial PF4/polyanion enzyme immunoassays (EIAs), both sensitive for detecting clinically relevant HIT antibodies. The gold standard test, Serotonin release assay (SRA), has high specificity and sensitively for HIT ${ }^{15}$.
Treatment is mandatory when high suspicion or confirmation of HIT. The principles are: (a) stop use and avoid any form of heparin; (b) start any anticoagulant nonheparin; (c) add warfarin after substantial platelet recovery (if warfarin has already begun, vitamin $\mathrm{K}$ must be used); (d) search for HIT antibodies; (e) investigate thrombosis of lower extremities and deep vein thrombosis; (f) avoid prophylactic platelet transfusion 1 .

\section{CONCLUSION}

Considering the large number of patients exposed to heparin, its major side effects must be known. HIT type II should be considered as differential diagnosis in patients with myocardial infarction and thrombocytopenia, since heparin use must be avoided and a specific therapeutic promptly applied.

\section{REFERENCES}

1. Warkentin TE. Heparin-Induced Thrombocytopenia: Diagnosis and Management. Circulation. 2004; 110:e454-e458.

2. Brieger $\mathrm{DB}$, Mak $\mathrm{KH}$, Kottke-Marchant $\mathrm{K}$, et al. Heparin-Induced Thrombocytopenia. J Am Coll Cardiol. 1998; 31(7):1449-1459.

3. Warkentin TE, Aird WC, Rand JH. Plateletendothelial interactions: sepsis, HIT, and antiphospholipid sydrome. Hematology (Am Soc Hematol Educ Program). 2003; 497-519.

4. Warkentin TE, Levine MN, Hirsh J, et al. Heparininduced thrombocytopenia in patients treated with low-molecular-weight heparin or unfractionated heparin. N Engl J Med. 1995; 332(2):1330-1335.

5. Warkentin TE. Heparin-induced thrombocytopenia: pathogenesis and management. $\mathrm{Br} \mathrm{J}$ Haematol. 2003; 121(4)535-555.

6. Selleng K, Warkentin TE, Greinacher A. Heparininduced thrombocytopenia in intensive care patients. Crit Care Med. 2007; 35(4):1165-1176.

7. Greinacher A, Farner B, Kroll $H$, et al. Clinical features of heparin-induced thrombocytopenia including risk factor for thrombosis. A retrospective analysis of 408 patients. Thromb Haemost. 2005; 94(1):132-5. 
8. Mak KH, Kottke-Marchant K, Brooks LM, Topol EJ. In vitro efficacy of platelet glycoprotein Ilb/IIla antagonist in blocking platelet function in plasma of patients with heparin-induced thrombocytopenia. Thromb Haemost. 1998; 80(6):989-993.

9. Girolami B, Prandoni P, Stefani PM, et al. The incidence of heparin-induced thrombocytopenia in hospitalized medical patients treated with subcutaneous unfractionated heparin: a prospective cohort study. Blood. 2003; 101(8):2955-2959.

10. Cines DB, Rauova L, Arepally G, et al. Heparininduced thrombocytopenia: an autoimmune disorder regulated through dynamic autoantigen assembly/disassembly. J Clin Apher. 2007; 22(1):31-36.

11. Kelton JG. Heparin-induced thrombocytopenia: an overview. Blood Rev. 2002; 16(1):77-80.

12. Rice L, Attisha WK, Drexler A, Francis JL. Delayed-onset heparin-induced thrombocytopenia. Ann Intern Med. 2002; 136(3):210-215.

13. Warkentin TE, Heddle NM. Laboratory diagnosis of immune heparin-induced thrombocytopenia. Curr Hematol Rep. 2003; 2:148-157.

14. Lo GK, Juhl D, Warkentin TE, et al. Evaluation of pretest clinical score (4 T's) for the diagnosis of heparin-induced thrombocytopenia in two clinical settings. J Thromb Haemost. 2006; 4:759-765.

15. Sheridan D, Carter C, Kelton JG. A diagnostic test for heparin-induced thrombocytopenia. Blood. 1986; 67(1):27-30. 